\title{
METODE VECTOR AUTOREGRESSIVE (VAR) DALAM PERAMALAN JUMLAH WISATAWAN MANCANEGARA KE BALI
}

\author{
Tjok Gde Sahityahutti Ranangga $^{1 \S}$, I Wayan Sumarjaya ${ }^{2}$, I Gusti Ayu Made Srinadi ${ }^{3}$ \\ ${ }^{1}$ Program Studi Matematika, Fakultas MIPA - Universitas Udayana [Email: tjokopa@gmail.com] \\ ${ }^{2}$ Program Studi Matematika, Fakultas MIPA - Universitas Udayana [Email: sumarjaya@ unud.ac.id] \\ ${ }^{3}$ Program Studi Matematika, Fakultas MIPA - Universitas Udayana [Email: srinadi@ unud.ac.id] \\ ${ }^{\S}$ Corresponding Author
}

\begin{abstract}
The purposes of this research were to model and to forecast the number of foreign tourists (Australia, China, and Japan) arrival to Bali using vector autoregressive (VAR) method. The estimated of VAR model obtained to forecast the number of foreign tourists to Bali is the sixth order VAR (VAR(6)).We used multivariate least square method to estimate the VAR(6)'s parameters.The mean absolute percentage error (MAPE) in this model were as follows $6.8 \%$ in predicting the number of Australian tourists, $15.9 \%$ in predicting the number of Chinese tourists, and 9\% in predicting the number of Japanese tourists. The prediction of Australian, Chinese, and Japanese tourists arrival to Bali for July 2017 to December 2017 tended to experience up and downs that were not too high compared to the previous months.
\end{abstract}

Keywords: forecasting, foreign tourists arrival to Bali, mean absolute percentage error (MAPE), vector autoregressive (VAR)

\section{PENDAHULUAN}

Peramalan adalah seni dan ilmu memprediksi peristiwa-peristiwa masa depan dengan pengambilan data historis dan memproyeksikannya ke masa depan menggunakan model matematis (Heizer et al., 2011). Peramalan berguna untuk memperoleh gambaran tentang masa yang akan datang, sehingga diperoleh kesiapan untuk mengantisipasi jika terjadi peristiwa-peristiwa yang tidak diinginkan. Peramalan tentu tidak akan menggambarkan kejadian atau peristiwa yang sebenarnya, tetapi dalam model matematis peramalan dapat dibuat sedemikian sehingga galat (error) peramalan (kesalahan peramalan) yang diperoleh adalah sekecil-kecilnya. Galat biasanya diukur dalam mean absolute error (MAE), mean absolute percentage error (MAPE), root mean square absolute percentage error (RMSAPE), dan lain-lain.

Metode analisis yang digunakan untuk mencari pengaruh data historis terhadap data yang akan datang agar memperoleh hasil peramalan adalah analisis deret waktu. Data yang digunakan dalam analisis ini harus memiliki interval yang sama, misalkan dalam harian, bulanan, atau tahunan. Analisis deret waktu dapat digunakan untuk menganalisis data yang terdiri satu variabel (univariate) dan data yang terdiri lebih dari satu variabel (multivariate). Kelemahan dari analisis deret waktu univariat adalah tidak diperhi-tungkannya pengaruh variabel-variabel lain di luar model yang mungkin saja memiliki pengaruh signifikan terhadap model karena pada analisis deret waktu univariat hanya dianalisis satu variabel terhadap data historisnya. Sedangkan pada analisis deret waktu multivariat dapat dianalisis hubungan dinamis antar variabel dan meramalkan data secara simultan (Tsay, 2014).

Adapun model deret waktu multivariat yang sering digunakan adalah fungsi transfer, analisis intervensi, analisis Fourier, analisis spektral, dan vector autoregressive (VAR). Metode VAR merupakan model deret waktu yang dapat 
digunakan untuk memodelkan dan meramalkan lebih dari satu variabel secara simultan. Menurut Gujarati (2004, p. 853) keunggulan dari metode VAR antara lain adalah (1) bentuk model sederhana, dengan tidak perlu khawatir dalam menentukan antara variabel endogen dan variabel eksogen, dalam model ini semua variabel adalah variabel endogen; (2) estimasi model VAR sederhana yaitu bisa menggunakan metode kuadrat terkecil (MKT); (3) hasil peramalan yang diperoleh dari metode ini lebih baik dibandingkan dengan model simultan kompleks lainnya.

Penelitian terkait metode VAR adalah Suprianto (2014) menggunakan model VAR untuk memodelkan utang luar negeri pemerintah, belanja negara, dan struktur perdagangan Indonesia. Hasil yang diperoleh pada pemodelan utang luar negeri pemerintah, belanja negara, dan struktur perdagangan Indonesia adalah model VAR dengan orde satu (VAR(1)). Model VAR pada penelitian tersebut digunakan untuk memodelkan variabel dari sektor ekonomi. Salah satu sektor ekonomi yang populer adalah bidang pariwisata.

Penelitian terkait model VAR dalam bidang pariwisata adalah Witt \& Song (2000) memodelkan kunjungan wisatawan Amerika. Pada penelitian Witt \& Song (2000) tersebut diperoleh hasil bahwa model VAR memiliki tingkat akurasi yang cukup baik dalam meramalkan kunjungan wisatawan Amerika. Berdasarkan penelitian tersebut, maka model VAR dapat menjadi rekomendasi model untuk meramalkan jumlah kunjungan wisatawan ke Bali.

Provinsi Bali merupakan salah satu daerah di Indonesia yang dominan dengan bidang pariwisata. Keindahan alam dan keunikan budaya Bali menyebabkan daerah ini menjadi daerah tujuan wisata yang terkenal sampai ke mancanegara. Hal ini dibuktikan dengan beberapa kegiatan-kegiatan internasional yang diadakan di Bali dan beberapa tokoh-tokoh dunia yang berkunjung ke Bali.

Jumlah kunjungan wisatawan man-canegara ke Bali merupakan salah satu indikator utama untuk mengukur per-kembangan kegiatan kepariwisataan (BPS Bali, 2017), sehingga peramalan jumlah kunjungan wisatawan mancanegara ke Bali perlu dilakukan. Pada tahun 2016 jumlah kunjungan wisatawan mancanegara ke Bali adalah sebanyak 4.927.937 jiwa. Jumlah ini meningkat sebesar $22,55 \%$ dari tahun sebelumnya. Tiga negara terbanyak yang mendatangkan warganya ke Bali adalah Australia sebesar 1.143.157 jiwa (23,20\%), Cina sebesar 990.771 jiwa $(20,11 \%)$, dan Jepang sebesar 235.009 jiwa (4,77\%). Ketiga negara tersebut menyumbang hampir $50 \%$ atau setengah dari total jumlah wistawan mancanegara yang berkunjung ke Bali (Dinas Pariwisata Provinsi Bali, 2017).

Penelitian ini bertujuan untuk memodelkan jumlah kunjungan wisatawan Australia, Cina, dan Jepang ke Bali menggunakan metode VAR dan memprediksi jumlah kunjungan wisatawan Australia, Cina, dan Jepang ke Bali.

\section{METODE PENELITIAN}

Jenis data yang digunakan dalam penelitian ini adalah data sekunder yaitu data jumlah kunjungan wisatawan Australia, Cina, dan Jepang ke Bali. Data diperoleh dari halaman web Dinas Pariwisata Provinsi Bali. Data yang digunakan adalah data bulanan dari Januari 2010 sampai Juni 2017. Data dari Januari 2010 sampai Agustus 2016 digunakan dalam pembentukan model dan data dari September 2016 sampai Juni 2017 digunakan untuk menguji keakuratan model meng-gunakan kriteria peramalan mean absolute percentage error (MAPE). Langkah-langkah analisis data yang dilakukan dalam pembentukan model VAR adalah sebagai berikut.

\section{Identifikasi Orde Model VAR}

Bentuk umum model VAR orde- $p$, dinotasikan $\operatorname{VAR}(p)$, untuk $K=3$ variabel deret waktu yaitu data jumlah kunjungan wisatawan Australia $\left(y_{1 t}\right)$, Cina $\left(y_{2 t}\right)$, dan Jepang $\left(y_{3 t}\right)$ ke Bali adalah sebagai berikut:

$$
\begin{aligned}
y_{t}= & v+A_{1} y_{t-1}+A_{2} y_{t-2}+\cdots+A_{p} y_{t-p} \\
& +u_{t}, t=0, \pm 1, \pm 2, \ldots
\end{aligned}
$$


dengan $y_{t}=\left(y_{1 t}, y_{2 t}, y_{3 t}\right)^{\prime}$ adalah matriks vektor berukuran $(3 \times 1), \quad A_{1}, A_{2}, A_{3}, \ldots, A_{p}$ adalah matriks koefisien berukuran $(3 \times 3)$, $v=\left(v_{1}, v_{2}, v_{3}\right)^{\prime}$ adalah vektor intersep berukuran $(3 \times 1)$, dan $u_{t}=\left(u_{1 t}, u_{2 t}, u_{3 t}\right)^{\prime}$ adalah galat model berukuran $(3 \times 1)$. Vektor $u_{t}$ diasumsikan sebagai proses white noise saling bebas rata-rata 0 dengan time-invariant, dengan kata lain, $E\left(u_{t}\right)=0, E\left(u_{t} u_{t}^{\prime}\right)=\Sigma_{u}$ dan $E\left(u_{t} u_{s}^{\prime}\right)=0$ untuk $s \neq t$.

Model VAR pada persamaan (1) dikatakan stabil apabila

$$
\begin{aligned}
& \operatorname{det}\left(I_{K}-A_{1} z-A_{2} z^{2}-\cdots-A_{p} z^{p}\right) \neq 0, \\
& |z| \leq 1
\end{aligned}
$$

yaitu persamaan (2) yang disebut sebagai reverse characteristic polynomial dari model $\operatorname{VAR}(p)$ tidak memiliki akar pada dan di dalam lingkaran unit (Lütkepohl, 2005).

Identifikasi orde optimum dari model $\operatorname{VAR}(p)$ menggunakan Likelihood Ratio(LR) Test, final prediction error (FPE), Akaike's Information Criterion (AIC), Hannan-Quinn Criterion (HQ), dan Schwarz Information Criterion (SC). Misalkan $M$ merupakan batas orde dari model VAR, urutan hipotesis untuk uji LR adalah sebagai berikut:

$$
\begin{gathered}
H_{0}^{1}: A_{M}=0 \quad \text { vs } H_{1}^{1}: A_{M} \neq 0 \\
H_{0}^{2}: A_{M-1}=0 \text { vs } H_{1}^{2}: A_{M-1} \neq 0 \mid A_{M}=0 \\
\vdots \\
H_{0}^{i}: A_{M-i+1}=0 \text { vs } \\
H_{1}^{i}: A_{M-i+1} \neq 0 \mid A_{M}=\cdots=A_{M-i+2}=0 \\
\quad \vdots \\
H_{0}^{M}: A_{1}=0 \text { vs } \\
H_{1}^{M}: A_{1} \neq 0 \mid A_{M}=\cdots=A_{2}=0
\end{gathered}
$$

Hipotesis diuji secara berurutan dan proses berhenti sampai menemukan hipotesis nol yang ditolak. Hal ini berarti, jika $H_{0}^{i}$ ditolak, maka $\hat{p}=M-i+1$ akan terpilih sebagai estimasi orde dari VAR. Statistik uji LR dirumuskan sebagai berikut:

$$
\lambda_{L R}(i)=T\left[\ln \left|\tilde{\Sigma}_{u}(M-i)\right|-\ln \left|\tilde{\Sigma}_{u}(M-i+1)\right|\right]
$$

Jika $\lambda_{L R}(i)>\chi_{K^{2} ; \alpha}^{2}$ atau $p$-value $<\alpha$, maka $H_{0}^{i}$ ditolak. Pemilihan orde berdasarkan FPE, AIC, HQ, dan SC berturut-turut dirumuskan sebagai berikut:

$$
\begin{aligned}
& \operatorname{FPE}(m)=\left(\frac{T+K m+1}{T-K m-1}\right)^{K} \operatorname{det}\left(\tilde{\Sigma}_{u}(m)\right) \\
& \operatorname{AIC}(m)=\ln \left|\tilde{\Sigma}_{u}(m)\right|+\frac{2 m K^{2}}{T} \\
& \operatorname{HQ}(m)=\ln \left|\tilde{\Sigma}_{u}(m)\right|+\frac{2 \ln (\ln T)}{T} m K^{2} \\
& \operatorname{SIC}(m)=\ln \left|\tilde{\Sigma}_{u}(m)\right|+\frac{\ln T}{T} m K^{2}
\end{aligned}
$$

dengan $T$ adalah banyak data, $K$ adalah banyak variabel, dan $\tilde{\Sigma}_{u}(m)$ merupakan penduga MLE dari $\Sigma_{u}$. Estimasi orde $(\hat{p})$ model yang dipilih adalah $\hat{p}=m$ sedemikian sehingga nilai kriteria $\operatorname{FPE}(m), \operatorname{AIC}(m), \operatorname{HQ}(m)$, dan $\operatorname{SIC}(m)$ yang dihasilkan adalah yang terkecil (L ü tkepohl, 2005).

\section{Estimasi Parameter Model}

Estimasi parameter model VAR yang digunakan adalah metode multivariate least square estimastion (MLS). Misalkan untuk setiap $K$ variabel deret waktu diberikan sampel berukuran $T$, yaitu $y_{1}, y_{2}, y_{3}, \ldots, y_{T}$ dan diberikan $p$ presample, yaitu $y_{-p+1}, y_{-p+2}$, $y_{-p+3}, \ldots, y_{0}$. Banyak data presample sama dengan orde optimum model yang terpilih pada langkah pertama. Digunakan notasi sebagai berikut:

$$
\begin{aligned}
& Y=\left(y_{1}, y_{2}, y_{3}, \ldots, y_{T}\right)_{(K \times T)} \\
& B=\left(v, A_{1}, A_{2}, \ldots, A_{p}\right)_{(K \times(K p+1))} \\
& Z_{t}=\left[\begin{array}{c}
1 \\
y_{t} \\
\vdots \\
y_{t-p+2} \\
y_{t-p+1}
\end{array}\right]_{((K p+1)+1)} \\
& Z=\left(Z_{0}, Z_{1}, Z_{2}, \ldots, Z_{T-1}\right)_{((K p+1) \times T)} \\
& U=\left(u_{1}, u_{2}, u_{3}, \ldots, u_{T}\right)_{(K \times T)}
\end{aligned}
$$

Dengan menggunakan notasi ini, untuk $t=$ $1,2,3, \ldots, T$, model $\operatorname{VAR}(p)$ pada persamaan (1) dapat dituliskan sebagai 


$$
Y=B Z+U
$$

dan penduga MLS dari $B$ adalah

$$
\begin{aligned}
\hat{B} & =\left[\hat{v}, \hat{A}_{1}, \hat{A}_{2}, \hat{A}_{3}, \ldots, \hat{A}_{p}\right] \\
& =Y Z^{\prime}\left(Z Z^{\prime}\right)^{-1}
\end{aligned}
$$

(Lütkepohl, 2005).

\section{Uji Asumsi Model}

Uji asumsi model dilakukan untuk mengecek asumsi-asumsi yang terdapat pada model. Asumsi-asumsi yang harus terpenuhi pada model agar model tersebut dapat digunakan untuk proses peramalan adalah tidak terjadi autokorelasi antarresidual, residual model menyebar normal, dan model merupakan proses yang stabil.

Untuk menguji autokorelasi antarresidual model digunakan uji Portmanteau. Hipotesis yang diuji adalah.

$H_{0}$ : tidak terjadi autokorelasi antarresidual model pada semua lag

$H_{1}$ : terdapat autokorelasi antarresidual model pada beberapa lag

Statistik uji untuk menarik kesimpulan dirumuskan sebagai berikut:

$$
\left.Q_{h}=T \sum_{j=1}^{h} \operatorname{tr}\left(\hat{C}_{j}^{\prime} \hat{C}_{j}^{-1} \hat{C}_{j} \hat{C}_{j}^{-1}\right)\right)
$$

dengan $\hat{C}_{j}=\sum_{t=i+1}^{T} \hat{u}_{t} \hat{u}_{t-i}^{\prime}$ dan $\hat{u}_{t}$ merupakan residual dari model $\operatorname{VAR}(p)$ yang stabil. Jika $Q_{h}>\chi_{K^{2}(h-p) ; \alpha}^{2}$ atau $p-$ value dari $Q_{h}<\alpha$, maka $H_{0}$ ditolak.

Untuk menguji kenormalan residual model digunakan uji Lomnicki-Jarque-Bera (LJB). Hipotesis yang diuji adalah sebagai berikut:

$$
\begin{aligned}
& H_{0}: \text { residual model menyebar normal } \\
& H_{1}: \text { residual model tidak menyebar } \\
& \text { normal }
\end{aligned}
$$

Statistik uji LJB dapat dilihat berdasarkan pada skewness dan kurtosis dari standardized residual model, yaitu $\hat{u}_{t}^{s}=\left(\hat{u}_{1 t}^{s}, \hat{u}_{2 t}^{s}, \ldots, \hat{u}_{K t}^{s}\right)^{\prime}=$ $\widetilde{\Sigma}_{u}^{-1 / 2}\left(\hat{u}_{t}-\overline{\hat{u}}\right)$. Skewness $\left(s_{3}^{2}\right)$ dan kurtosis $\left(s_{4}^{2}\right)$ dari $\hat{u}_{t}^{s}$ dirumuskan sebagai berikut:

$$
S_{3}^{2}=\frac{T \mathbf{b}_{1}^{\prime} \mathbf{b}_{1}}{6}
$$

dan

$$
S_{4}^{2}=\frac{T\left(\mathbf{b}_{2}-3_{K}\right)^{\prime}\left(\mathbf{b}_{2}-3_{K}\right)}{24}
$$

dengan $\mathbf{b}_{1}=\left(b_{11}, b_{12}, b_{13}, \ldots, b_{1 K}\right)^{\prime} ; b_{1 k}=$ $\frac{1}{T} \sum_{t=1}^{T}\left(\hat{u}_{k t}^{s}\right)^{3} \quad, \quad k=1,2,3, \ldots, K \quad ; \quad \mathbf{b}_{2}=$ $\left(b_{21}, b_{22}, b_{23}, \ldots, b_{2 K}\right)^{\prime} ; b_{2 k}=\frac{1}{T} \sum_{t=1}^{T}\left(\hat{u}_{k t}^{s}\right)^{4}$, $k=1,2,3, \ldots, K ; \mathbf{3}_{K}=(3,3,3, \ldots, 3)^{\prime}$ vektor berukuran $(K \times 1)$.

Berdasarkan persamaan (11) dan (12) diperoleh statistik uji Lomnicki-Jarque-Bera sebagai berikut:

$$
L J B_{K}=s_{3}^{2}+s_{4}^{2}
$$

Jika $L J B_{K}>\chi_{2 K ; \alpha}^{2}$ atau $p$-value dari $L J B_{K}<\alpha$, maka $H_{0}$ ditolak.

Untuk mengecek kestabilan model VAR dapat dilihat dari akar reverse characteristic polynomial model tersebut seperti pada persamaan (2).

\section{Kriteria Peramalan}

Kriteria peramalan yang digunakan untuk melihat seberapa akurat model dalam memprediksi kejadian yang sebenarnya adalah mean absolute percentage error (MAPE). Nilai MAPE yang semakin kecil mengindikasikan bahwa hasil peramalan semakin mendekati hasil yang aktual. MAPE dirumuskan sebagai berikut:

$$
M A P E=\frac{1}{m} \sum_{t=1}^{m} \frac{\left|y_{t}-\bar{y}_{t}\right|}{y_{t}} \times 100 \%
$$

dengan $m$ merupakan banyak data yang digunakan menghitung MAPE, $\bar{y}_{t}$ merupakan hasil peramalan, dan $y_{t}$ merupakan nilai yang sesungguhnya dari variabel yang diprediksi. Menurut Zhang et al. (2015) kriteria peramalan MAPE dapat dilihat dalam Tabel 1.

Tabel 1. Kriteria Nilai MAPE

\begin{tabular}{|l|l|}
\hline \multicolumn{1}{|c|}{ MAPE } & \multicolumn{1}{c|}{ Kekuatan Peramalan } \\
\hline$<10 \%$ & Peramalan sangat akurat \\
\hline $10 \%-20 \%$ & Peramalan baik \\
\hline $20 \%-50 \%$ & $\begin{array}{l}\text { Peramalan masuk akal } \\
\text { (wajar) }\end{array}$ \\
\hline$>50 \%$ & Peramalan tidak akurat \\
\hline
\end{tabular}




\section{Peramalan}

Misalkan dimiliki data historis sampai waktu $t$, maka nilai peramalan untuk $h$ periode waktu ke depan dirumuskan sebagi berikut:

$$
\begin{aligned}
& \bar{y}_{t}(h)=E_{t}\left(y_{t+h}\right) \\
& =v+A_{1} E_{t}\left(y_{t+h-1}\right)+\cdots+A_{p} E_{t}\left(y_{t+h-p}\right)
\end{aligned}
$$

Persamaan (15) dapat digunakan secara rekursif untuk menghitung prediktor $h$ langkah unit waktu ke depan dimulai dari $h=1$.

\section{HASIL DAN PEMBAHASAN}

\section{Identifikasi Model VAR}

Data yang digunakan dalam melakukan pemilihan orde optimum dari model adalah data jumlah kunjungan wisatawan Australia, Cina, dan Jepang ke Bali pada Januari 2010 sampai Agustus 2016 yang telah ditransformasi menggunakan transformasi natural logarithm (ln) . Transformasi data dilakukan untuk membuat model yang diperoleh menjadi stabil karena pada penelitian ini model yang diperoleh tanpa mentransformasi data adalah model yang tidak stabil. Perhitungan nilai uji LR ( $\alpha=5 \%)$, FPE, AIC, SC, dan HQ menggunakan software EViews dan hasilnya dapat dilihat pada Tabel 2.

Tabel 2. Nilai LR, FPE, AIC, SC, dan HQ

\begin{tabular}{|c|l|l|l|l|l|}
\hline $\begin{array}{c}\text { La } \\
\mathrm{g}\end{array}$ & \multicolumn{1}{|c|}{ LR } & FPE & AIC & SC & HQ \\
\hline 0 & - & 0,000203 & 0,009 & 0,107 & 0,048 \\
\hline 1 & 97,613 & 0,0000575 & $-1,251$ & $-0,860$ & $-1,096$ \\
\hline 2 & 38,851 & 0,0000397 & $-1,623$ & $\mathbf{- 0 , 9 3 8}$ & $-1,352$ \\
\hline 3 & 22,036 & 0,0000355 & $-1,739$ & $-0,760$ & $-1,351$ \\
\hline 4 & 21,240 & 0,0000317 & $-1,860$ & $-0,587$ & $-1,356$ \\
\hline 5 & 23,521 & 0,0000266 & $-2,048$ & $-0,481$ & $-1,427$ \\
\hline 6 & $\mathbf{2 0 , 1 1 5}$ & $\mathbf{0 , 0 0 0 0 2 3 4}$ & $-2,194$ & $-0,333$ & $\mathbf{- 1 , 4 5 6}$ \\
\hline 7 & 12,482 & 0,0000239 & $\mathbf{- 2 , 2 0 0}$ & $-0,046$ & $-1,347$ \\
\hline 8 & 6,815 & 0,0000276 & $-2,094$ & 0,354 & $-1,124$ \\
\hline 9 & 13,776 & 0,0000267 & $-2,174$ & 0,568 & $-1,087$ \\
\hline 10 & 7,760 & 0,00003 & $-2,119$ & 0,917 & $-0,916$ \\
\hline 11 & 5,309 & 0,0000361 & $-2,010$ & 1,319 & $-0,691$ \\
\hline 12 & 11,344 & 0,0000361 & $-2,111$ & 1,512 & $-0,676$ \\
\hline
\end{tabular}

Orde optimum yang terpilih berdasarkan masing-masing kriteria dapat dilihat pada Tabel 2 dengan nilai dalam sel yang ditebalkan. Dapat dilihat bahwa orde enam terpilih berdasarkan tiga kriteria yaitu uji LR, FPE, dan HQ. Jadi, orde model VAR dari data transformasi ln jumlah kunjungan wisatawan Australia (lnAus), Cina (lnCin), dan Jepang (lnJep) ke Bali yang dipilih adalah enam.

\section{Estimasi Parameter Model}

Estimasi parameter model VAR menggunakan metode MLS. Sama halnya dengan tahap sebelumnya data yang digunakan dalam MLS adalah data $\ln A u s, \operatorname{lnCin}$, dan $\operatorname{lnJep}$ ke Bali dari Januari 2010 sampai Agustus 2016. Karena orde optimum yang terpilih adalah enam, maka terdapat $p=6$ data presample (Januari 2010-Juni 2010) dan $T=74$ data sample (Juli 2010-Agustus 2016). Perhitungan mencari nilai penduga parameter seperti pada persamaan (9) menggunakan software MaTlab. Diperoleh estimasi model VAR sebagai berikut:

$$
\begin{aligned}
& {\left[\begin{array}{l}
\ln \mathrm{Aus}_{t} \\
\ln \mathrm{in}_{t} \\
\operatorname{lnJep}_{t}
\end{array}\right]=\left[\begin{array}{c}
10,82451 \\
-5,501368 \\
6,682137
\end{array}\right]+A_{1}\left[\begin{array}{l}
\ln \mathrm{Aus}_{t-1} \\
\ln \mathrm{Cin}_{t-1} \\
\ln \mathrm{ep}_{t-1}
\end{array}\right]} \\
& +A_{2}\left[\begin{array}{l}
\ln \mathrm{Aus}_{t-2} \\
\operatorname{lnCin}_{t-2} \\
\ln \mathrm{Jep}_{t-2}
\end{array}\right]+A_{3}\left[\begin{array}{l}
\ln \mathrm{Aus}_{t-3} \\
\operatorname{lnCin}_{t-3} \\
\operatorname{lnJep}_{t-3}
\end{array}\right]+A_{4}\left[\begin{array}{l}
\ln \mathrm{Aus}_{t-4} \\
\operatorname{lnCin}_{t-4} \\
\operatorname{lnJep}_{t-4}
\end{array}\right] \\
& +A_{5}\left[\begin{array}{l}
\ln \mathrm{Aus}_{t-5} \\
\operatorname{lnCin}_{t-5} \\
\ln \mathrm{jep}_{t-5}
\end{array}\right]+A_{6}\left[\begin{array}{l}
\ln \mathrm{Aus}_{t-6} \\
\ln C i n_{t-6} \\
\operatorname{lnJep}_{t-6}
\end{array}\right]
\end{aligned}
$$

dengan

$$
\begin{aligned}
A_{1} & =\left[\begin{array}{ccc}
0,195793 & -0,045767 & -0,049052 \\
0,576245 & 0,199267 & -0,278286 \\
0,059604 & 0,016329 & 0,380036
\end{array}\right] \\
A_{2} & =\left[\begin{array}{ccc}
0,115967 & 0,172786 & -0,333171 \\
-0,122193 & 0,141294 & 0,012942 \\
0,149158 & 0,004047 & -0,0857
\end{array}\right] \\
A_{3} & =\left[\begin{array}{ccc}
0,467309 & 0,096959 & 0,132568 \\
0,346406 & -0,160993 & -0,260952 \\
0,273622 & -0,066455 & 0,131414
\end{array}\right]
\end{aligned}
$$




$$
\begin{aligned}
& A_{4}=\left[\begin{array}{ccc}
-0,280125 & 0,018938 & 0,016856 \\
0,550731 & 0,249695 & -0,166425 \\
-0,36865 & -0,073866 & -0,040091
\end{array}\right] \\
& A_{5}=\left[\begin{array}{ccc}
-0,271053 & 0,025376 & 0,068259 \\
-0,27825 & 0,272622 & 0,222292 \\
0,128325 & 0,133524 & 0,037079
\end{array}\right] \\
& A_{6}=\left[\begin{array}{ccc}
-0,166169 & 0,011568 & -0,167049 \\
-0,358695 & 0,152685 & 0,376803 \\
-0,502256 & 0,159778 & 0,005395
\end{array}\right]
\end{aligned}
$$

\section{Uji Asumsi Model}

Pertama dilakukan uji autokorelasi antarresidual model menggunakan uji portmanteau yang statistik ujinya seperti pada persamaan (10). Data yang digunakan untuk membentuk model VAR berjumlah 80 data yaitu dari Januari 2010 sampai Agustus 2016 dengan orde optimum yang dipilih adalah enam. Hal ini berarti beda kala (lag) autokorelasi antar residual terbesar yang dapat terbentuk adalah 73 . Oleh karena itu, hipotesis yang diuji adalah sebagai berikut.

$$
\begin{aligned}
H_{0}: & \text { tidak terjadi autokorelasi antarresidual } \\
& \text { model dari lag } 1 \text { sampai lag } 73 \\
H_{1} & : \text { terdapat autokorelasi antarresidual } \\
& \text { model pada beberapa lag dari lag } 1 \\
& \text { sampai lag } 73
\end{aligned}
$$

Perhitungan mencari nilai statistik uji $Q_{73}$ pada persamaan (10) dibantu menggunakan software Eviews. Diperoleh nilai $Q_{73}=$ 314,0494 dengan nilai $p$-value $=1,0000$. Penarikan keputusan menggunakan $\alpha=5 \%$. Karena nilai $p$-value dari $Q_{73}$ lebih besar dari $5 \%$, maka tidak cukup bukti untuk menolak $H_{0}$. Jadi, tidak terjadi autokorelasi antarresidual pada estimasi model VAR persamaan (16).

Selanjutnya dilakukan uji kenormalan residual estimasi model VAR menggunakan uji Lomnicki-Jarque-Bera (LJB). Hipotesis yang diuji adalah sebagai berikut:

$H_{0}$ : residual model menyebar normal

$H_{1}$ : residual model tidak menyebar normal
Perhitungan mencari nilai statistik uji $L J B_{3}$ pada persamaan (13) dibantu menggunakan software Eviews. Diperoleh nilai $L J B_{3}=$ 9,23393 dengan nilai $p$-value $=0,1608$. Penarikan keputusan menggunakan $\alpha=5 \%$. Karena nilai $p$-value dari $L J B_{3}$ lebih besar dari $5 \%$, maka tidak cukup bukti untuk menolak $H_{0}$. Jadi, residual estimasi model VAR pada persamaan (16) menyebar normal.

Terakir dilakukan uji kestabilan estimasi model VAR pada persamaan (16). Kestabilan model dapat dilihat dari akar reverse characteristics polynomial-nya yaitu

$$
\begin{aligned}
& \operatorname{det}\left(I_{3}-A_{1} z-A_{2} z^{2}-\cdots-A_{6} z^{6}\right) \neq 0, \\
& \quad|z| \leq 1
\end{aligned}
$$

dengan $A_{1}, A_{2}, A_{3}, A_{4}, A_{5}, A_{6}$ seperti pada persamaan (16). Perhitungan mencari akar-akar persamaan (17) menggunakan software MaTlab. Diperoleh hasil sebagai berikut:

Tabel 3. Akar-akar reverse characteristics polynomial

\begin{tabular}{|l|r|}
\hline \multicolumn{1}{|c|}{ Akar } & \multicolumn{1}{c|}{ Modulus } \\
\hline$-4,7838$ & 4,7838 \\
\hline-14110 & 1,4110 \\
\hline 1,2689 & 1,2689 \\
\hline 1,0004 & 1,0004 \\
\hline 1,2079 & 1,2079 \\
\hline 1,9635 & 1,9635 \\
\hline$-0,8822+1,4286 i$ & 1,6790 \\
\hline$-0,8822-1,4286 i$ & 1,6790 \\
\hline$-0,8716-0,9045 i$ & 1,2562 \\
\hline$-0,8716+0,9045 i$ & 1,2562 \\
\hline$-0,4877+0,9903 i$ & 1,1039 \\
\hline$-0,4877-0,9903 i$ & 1,1039 \\
\hline $0,0839-1,2725 i$ & 1,2752 \\
\hline $0,0839+1,2725 i$ & 1,2752 \\
\hline $0,5091-0,9090 i$ & 1,0419 \\
\hline $0,5091+0,9090 i$ & 1,0419 \\
\hline $0,9412-0,5158 i$ & 1,0733 \\
\hline $0,9412+0,5158 i$ & 1,0733 \\
\hline
\end{tabular}

Berdasarkan Tabel 3 dapat dilihat bahwa nilai modulus akar-akar persamaan (17) berada di luar lingkaran unit. Jadi, estimasi model VAR pada persamaan (16) adalah model yang stabil. 


\section{Kriteria Peramalan}

Kriteria peramalan yang digunakan untuk menguji keakuratan estimasi model VAR adalah mean absolute percentage error (MAPE). Data aktual yang digunakan untuk mencari nilai MAPE data jumlah kunjungan wisatawan Australia, Cina, dan Jepang ke Bali dari September 2016 sampai Juni 2017 dan data hasil peramalan diperoleh melalui persamaan (16). Perhitungan nilai MAPE menggunakan software EViews. Diperoleh nilai MAPE pada peramalan jumlah kunjungan wisatawan Australia, Cina, dan Jepang ke Bali berturut-turut adalah 6,8\%; $15,9 \%$; dan $9 \%$. Nilai-nilai tersebut mengindikasikan bahwa estimasi model VAR pada persamaan (16) memberikan hasil peramalan yang baik dalam meramalkan jumlah kunjungan wisatawan Cina dan memberikan hasil peramalan yang akurat dalam meramalkan jumlah kunjungan wisatawan Australia dan Jepang.

\section{Peramalan dengan Model VAR}

Berikut hasil peramalan jumlah kunjungan wisatawan Australia, Cina, dan Jepang ke Bali dengan menggunakan estimasi model VAR pada persamaan (16) dari Juli 2017 sampai Desember 2017.

Tabel 4. Peramalan Jumlah Wisatawan Australia, Cina, dan Jepang Tahun 2017

\begin{tabular}{|l|r|c|c|}
\hline \multicolumn{1}{|c|}{ Bulan } & Australia & Cina & \multicolumn{1}{c|}{ Jepang } \\
\hline Juli & 107.896 & 116.606 & 23.891 \\
\hline Agustus & 102.293 & 135.374 & 22.984 \\
\hline September & 100.716 & 126.420 & 25.466 \\
\hline Oktober & 112.161 & 115.083 & 23.846 \\
\hline Nopember & 103.921 & 127.649 & 23.323 \\
\hline Desember & 98.062 & 125.802 & 22.989 \\
\hline
\end{tabular}

\section{KESIMPULAN DAN SARAN}

Berdasarkan hasil dan pembahasan yang telah dipaparkan pada bab sebelumnya, model vector autoregressive (VAR) yang dibentuk menggunakan data transformasi natural logarithm (ln) jumlah kunjungan wisatawan Australia, Cina, dan Jepang ke Bali memiliki orde optimum enam dengan estimasi parameter model menggunakan metode multivariate least square estimastion (MLS). Berdasarkan nilai MAPE model tersebut memberikan hasil peramalan yang baik dalam meramalkan jumlah kunjungan wisatawan Cina $(15,9 \%)$ dan memberikan hasil peramalan yang akurat dalam meramalkan jumlah kunjungan wisatawan Australia (6,8\%) dan Jepang (9\%).

Peramalan jumlah wisatawan Australia, Cina, dan Jepang yang berkunjung ke Bali dari Juli 2017 sampai Desember 2017 cenderung mengalami naik turun yang tidak terlalu tinggi dibandingkan dengan bulan sebelumnya.

Saran untuk penelitian selanjutnya yaitu diharapkan menambahkan variabel lain yang mempengaruhi jumlah kunjungan wisatawan mancanegara ke Bali, seperti nilai tukar matang uang negara asal wisatawan terhadap rupiah yang bisa menjadi bahan pertimbangan bagi wisatawan untuk berkunjung ke Bali. Selain itu, untuk peneitian selanjutnya diharapkan menganalisis hubungan dinamis antarvariabel pada model VAR.

\section{DAFTAR PUSTAKA}

BPS Bali, 2017. Statistik Wisatawan Mancanegara ke Bali 2015. [Online] Available at: http://bali.bps.go.id/index. php/publikasi [Accessed 27 Februari 2017].

Dinas Pariwisata Provinsi Bali, 2017. Kedatangan Wisatawan Mancanagera yang Langsung ke Bali Berdasarkan Kebangasaan Setiap Bulan. [Online] Available at: http://www.disparda. baliprov.go.id [Accessed 27 Februari 2017].

Gujarati, D.N., 2004. Basic Econometrics. New York: McGraw-Hill.

Heizer, J., Render, B. \& Munson, C., 2011. Operations Management Sustainability and Supply Chain Management. Boston: Pearson.

Lutkepohl, H., 2005. New Introductions to Multiple Time Series Analysis. Berlin: Springer. 
Suprianto, 2014. Model VAR Untuk Pemodelan Utang Luar Negeri Pemerintah, Belanja Negara, dan Struktur Perdagangan Indonesia. Jurnal Mahasiswa Statistik, II(5), pp.369-372.

Tsay, R.S., 2014. Multiariate Time Series Analysis With $R$ and Financial Applications. New Jersey: John Wiley \& Sons.

Witt, S.F. \& Song, H., 2000. Tourism Demand Moddeling and Forecasting: Modern Econometric and Approaches. New York: Routlege.

Zhang, T., Wang, K. \& Zhang, X., 2015. Modelling and Analyzing the Transmission Dynamics of HBV Epidemic in Xinjiang, China. Plos One, X(9), pp.110-121. 